\title{
DEVICE FOR CALCULATE OF SWABS
}

\author{
CERVINKA, L[udek] \& KVAS, M[arek]
}

Abstract: This article describes counting of hygienic needs. Hygienic needs are swabs that are using in during doctor's operations. Swabs have many different tips. Every tip has specific using and problem for manufacturer is fast counting different swabs. Principle of calculating swabs and prototype of device is described in this article. Principle of calculating is using method of computer vision. Device acquires a picture and algorithm computes number of swabs in picture

Key words: computer vision, signal processing, triangulation

\section{INTRODUCTION}

The computer vision has many different applications. The field of use is very large. Detection by camera may by use in security, final inspection of product, detection of defect and many more applications. The device that is described in this article is using for counting of hygienically swabs.

Fast and correct count of number swabs stand for human count. This device has been developed for automatic count of swabs.

There are many types of swabs. The high number of different swabs may lead to many problems. The swab varies in dimension, surface or color. Every of these differences influences counting swabs. For this reason the device and its software have to be very robust.

Using of computer vision is a very fast and elegant solution of this problem. Besides, the installation of device is fast and cheap.

\section{HARDWARE PART}

The device is consisted of two parts. The first one is the hardware and the other one is the software. The hardware doesn't mean only a camera and a computer. It contains also a laser and cables.

There is a specific position for a camera, a laser and a detected swab. For detection, we use a triangulation effect. An angle between camera and laser makes a typical light profile on the swabs. The situation is shown at the Figure 1.

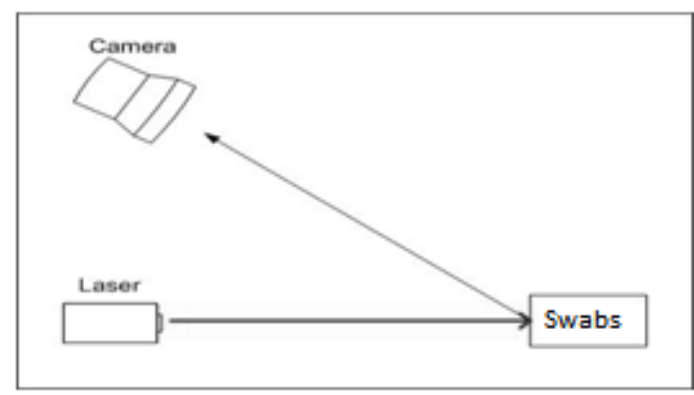

Fig. 1. Position of hardware

\subsection{Laser}

The counting of swabs directly from image is a very difficult task. For this reason we use an additional laser. The laser ray creates a typical pattern on the swabs. By using the laser the detection and the counting of swabs are easier and faster than without using it. This situation is illustrated at Figure 2.

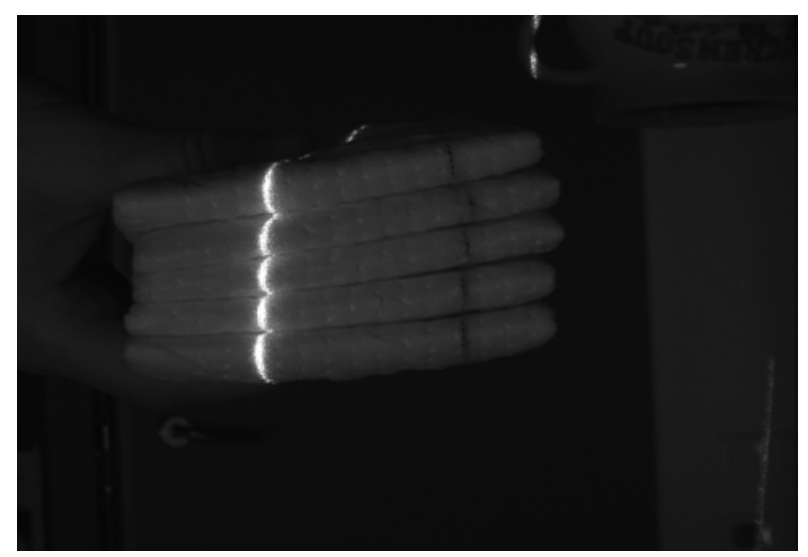

Fig. 2. Characteristic shape of laser on swabs surface

\subsection{Triangulation}

This principle of using laser and camera is called an active triangulation. The active triangulation is used for measuring shapes of objects.

The triangulation is used as a shape detector of swabs: Falling laser ray creates an arc on the swab. The radius of arc depends on a base in the triangulation. The base is a distance between the camera and the laser.

To set an optimal base is a difficult task, because the device may scan different swabs. A type of swab influences amplitude of the arc. This problem is compensated with software.

\subsection{Disadvantages of triangulation}

Using of an active triangulation has some troublesome influence. As the first disadvantage we can mention an ambient illumination. This disadvantage is compensated by using a color laser (red) and a color filter in camera.

The second disadvantage is a changing scale. The image resolution of the scanning swabs depends on the distance between swabs and the camera. If swabs are far, the resolution is low. The low resolution may lead a wrong analyze. This problem is compensated with software and it will be described later.

\section{SOFTWARE PART}

In the following part of this article we will describe the software analyse image. The software part is the main part of this device.

\subsection{Preprocessing image data}

If we have image than as in Fig. 2, we are able to start software analyse of number swabs at image. Sequence of a operation shows flowchart at Figure 3. 


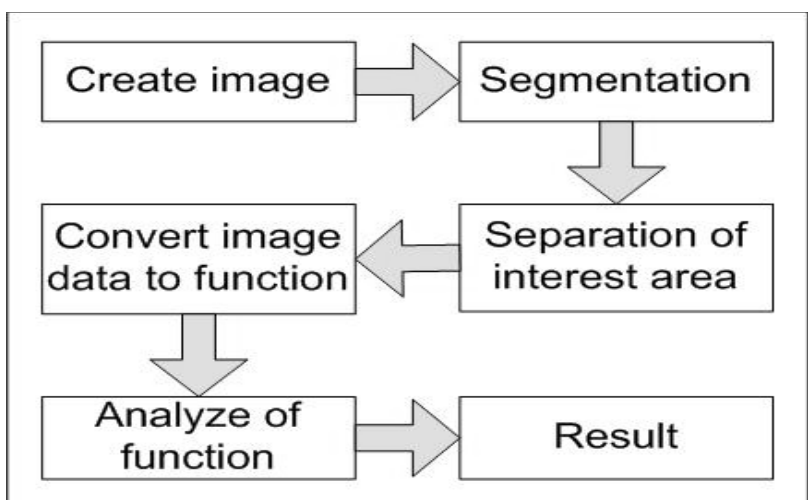

Fig. 3. Flowchart

The first step is to segment image data. Due to using a mono color camera it isn't possible to segment data according to colors. The parameter of segmentation is got from the histogram. The surface of swab has light diffusion and the segmented area isn't continuous.

The second step of preprocessing is to clear a fake areas data and to select an area with correct data.

Fake data is caused by a reflection of laser on another object in a background. It could be a hand, a laser ray on top of swab or another object in a scene. These data are cleared.

Now we have only correct data, but these data aren't in the correct position. The area with data is rotated because of active triangulation which makes a perspective projection. In the next step we need rotate data in image to a vertical position. To rotate to the correct position standard rotation transformation is used.

$$
\left[\begin{array}{l}
x^{\prime} \\
y^{\prime}
\end{array}\right]=\left[\begin{array}{cc}
\cos \theta & -\sin \theta \\
\sin \theta & \cos \theta
\end{array}\right]\left[\begin{array}{l}
x \\
y
\end{array}\right]
$$

The area with vertical data is easy selected to a smaller image now. This image is in Figure 4

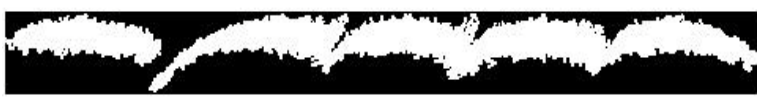

Fig. 4. Area with data (transposition image)

Every arc at figure 4 represents one swab. The next step is to transfer 2D data function $f(x, y)$ to 1D function $g(x)$. A function $g(x)$ represents a value $y$ at position $x$. The transformation of the function is very simple. We have to reduce axis $y$ in $f(x, y)$ to a single value. This value represents a position of center in axis $y$ (we have to find a center of data for axis $y$ for every position of $x$ ). The result is at Figure 5 .

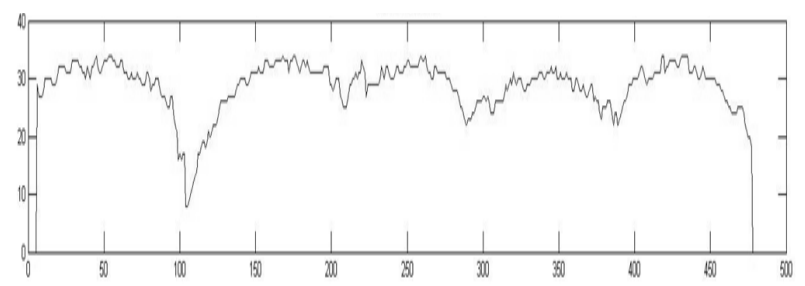

Fig. 5. Function $g(x)$ after transformation from function $f(x, y)$

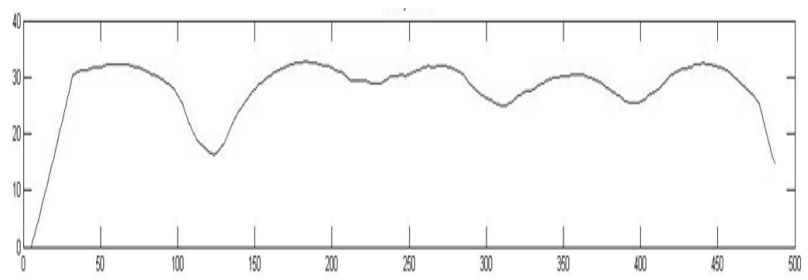

Fig. 6. Function $g(x)$ after filtration
For now we have function $g(x)$, which represents number of swabs. The next step is to analyse a function $g(x)$. The analyse is problematic, but the shape of function is noisy. For reduce noise an average filter is used. After filtration it is possible to use the first and the second derivation for identify the number of swabs in signal.

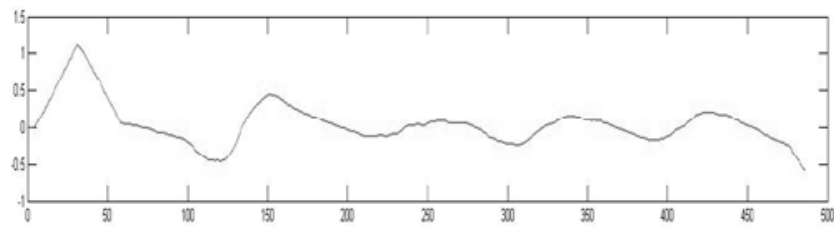

Fig. 7. Derivation of $g(x)$

In the first derivation function $\mathrm{g}^{\prime}(\mathrm{x})$ and the second derivation $\mathrm{g}^{\text {" }}(\mathrm{x})$ algorithm finds the maximal and the minimal values and calculates the number of swabs at the function $g(x)$ and at the image.

\subsection{Problem of classification and future work}

This method of classification has some disadvantages. The first problem is to filtrate noise. The order of the filter automatically sets for different types of the swabs, but algorithm sets wrong order of filter in a few cases, . This part of signal analyze will be improve.

The second problem of classification is a fact that swabs may have different color, surface or structure. This problem solves an adaptive segmentation. But in a few cases the segmentation can be wrong. For better result a control of exposure time will be implemented.

\section{CONCLUSION}

This article describes a device for counting number of swabs. This device is still in research and the prototype of device is used for testing algorithms.

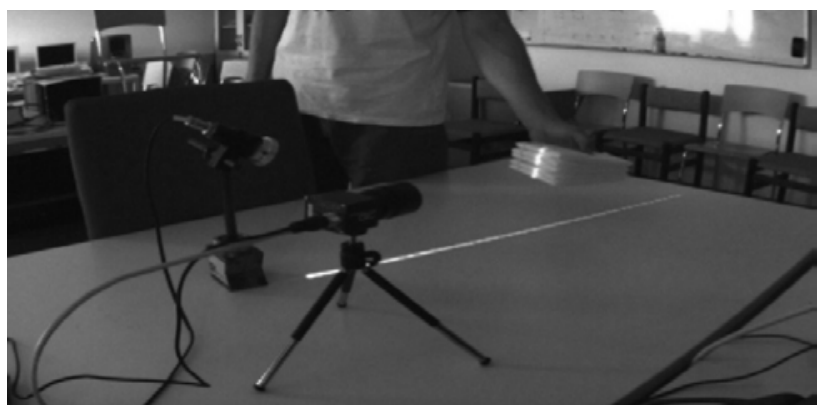

Fig. 8. Prototype of the device

\section{ACKNOWLEDGEMENTS}

This work has been supported Grant Agency of the Czech Republic (102/09/H081 SYNERGY - Mobile Sensoric Systems and Networks) and by Brno University of Technology. Without kind support of the above-mentioned agencies and institutions the presented research and development would not be possible and CAK 1M0567 supported too.

\section{REFERENCES}

Jan, J.; Medical image processing, reconstruction and Restoration, Taylor\&Francis 2006, ISBN 0-8247-5849-8, USA

Šonka, M.; Hlaváč, V. \& Boyle, R., Image Processing, Analysis, and Machine Vision. Thomson, Toronto, 2008. ISBN 978-0-495-08252-1

Žára, J.; Beneš, B. \& Felkel, P., Moderní počitačová grafika. Computer Press, 1998. ISBN 80-7226-049-9. Praha

Hlaváč, V. \& Šonka, M. Počítačové vidění. Grada, 1992. ISBN 80-85424-67-3. Praha 